\title{
Os Estudos de Tradução na Universidade Federal do Rio Grande do Norte
}

\author{
Translation Studies at Universidade Federal do Rio Grande do Norte
}

\begin{abstract}
Katia Aily Franco de Camargo* kafcamargo@gmail.com

Francisco Ernesto Zaragoza Zaldívar* franciscozar@gmail.com

Marcela Aparecida Cucci Silvestre* mcsilvestre@ect.ufrn.br

Orison Marden Bandeira de Melo Júnior* junori36@uol.com.br
\end{abstract}

RESUMO: Os estudos da tradução, uma nova disciplina acadêmica voltada aos fenômenos da tradução, têm sido estruturados na Universidade Federal do Rio Grande do Norte (UFRN) com vistas a formar não só tradutores, mas estudiosos da tradução. O presente artigo tem por objetivo, portanto, apresentar essa estruturação e a sua relevância local e institucional. Para tal, apresentamos os objetivos do Plano de Desenvolvimento Institucional da UFRN e do papel que ela ocupa no estado do Rio Grande do Norte. Em seguida, traçamos um histórico dos cursos de línguas estrangeiras e como eles abarcam os Estudos da Tradução e discutimos, de forma sucinta, conceitos relevantes para a área da tradução e as competências necessárias ao ato tradutológico. Por fim, relatamos a experiência da primeira oficina de tradução, ministrada no segundo semestre de 2016. Concluímos que, apesar de os participantes não estarem cientes das perspectivas dos estudos em tradução, eles adotaram algumas delas, o que mostrou a necessidade de um trabalho contínuo com os alunos que queiram adentrar o rico campo dos estudos da tradução.

PALAVRAS-CHAVE: Estudos da tradução. Oficina de Tradução. UFRN

ABSTRACT: Translation studies, a new academic area that is concerned with the phenomena of translation, have been organized at the Universidade Federal do Rio Grande do Norte (UFRN) in order to educate not only translators, but also translation scholars. This article aims to present, thus, the process of organization and the local and institutional relevance of this academic field. To do so, we presented the objectives of UFRN's Plano de Desenvolvimento Institucional [Institutional Development Plan] and the role the University plays in the state of Rio Grande do Norte. Then, we outlined the history of the foreign language undergraduate programs and showed how they encompass translation studies. Besides, we briefly discussed relevant concepts related to translation and the necessary competences to the translation process. Finally, we reported the experience of holding the first workshop

\footnotetext{
Professores da Universidade Federal do Rio Grande do Norte.
} 
in translation in the first semester of 2016. We concluded that, despite students' lack of knowledge about the different perspectives in translation studies, they adopted some of them, which showed us the need to continually work on translation with the students who want to explore this rich area of translation studies.

KEYWORDS: Translation studies. Workshop on translation. UFRN

\section{Introdução}

Jeremy Munday, em Introducing Translation Studies (2001), define Estudos da Tradução como uma nova disciplina acadêmica que se volta ao "estudo da teoria e dos fenômenos da tradução" (p. 1; nossa tradução) ${ }^{1}$. Diante disso, para o autor, essa disciplina é, por natureza, multilíngue e interdisciplinar, pois abrange várias áreas do conhecimento, como a linguística, a teoria literária, os estudos da comunicação, a filosofia, os estudos culturais, entre outras.

Andrew Chesterman apresenta, em sua obra Memes of translation: the spread of ideas in translation theory (1997), alguns estágios pelos quais os Estudos da Tradução passaram (p. 48-49). Cada estágio recebe um título que corresponde a aspectos específicos de determinada fase dos estudos. Eles são: (1) Estágio da Palavra - estudo dos aspectos semânticos e lexicais (significados convencional das palavras); (2) Estágio da Palavra de Deus - estudos voltados a questões de fidelidade aos textos-fonte, sendo sustentados por aspectos formais da língua; (3) Estágio da Retórica - estudos que se voltam à recepção, pois enfatizam a lealdade do tradutor ao leitor e a importância de um texto-alvo que seja fluente; (4) Estágio do Logos - estudos que priorizam a criatividade do tradutor, trazendo à tona questões de cunho estético; (5) Estágio Linguístico - estudos contrastivos que buscam encontrar semelhanças e diferenças entre os sistemas das línguas em comparação e as relações entre tais sistemas; (6) Estágio Comunicativo - estudos voltados aos aspectos comunicativos (funcional e pragmático) da língua que tornam o tradutor um membro desse evento comunicativo; (7) Estágio Alvo - estudos que apontam para o poder que tradutores exercem no processo tradutório ao produzir traduções que se conformam ou quebram normas estabelecidas; e (8) Estágio Cognitivo - estudos que colocam o tradutor no centro do ato tradutório, buscando respostas sobre as decisões por ele tomadas e o porquê delas.

\footnotetext{
${ }^{1}$ Texto original: "study of the theory and phenomena of translation".
} 
Esses estágios mostram a complexidade da área dos Estudos da Tradução e as possibilidades amplas de pesquisa para o estudioso/pesquisador da área. Segundo Chesterman (1997), essas possibilidades devem estar embasadas em diferentes perspectivas que conduzirão os seus estudos:

(a) intertextual - análise das relações formais, semânticas, estilísticas e pragmáticas entre os textos fonte e alvo, bem como as relações de fundo entre as línguas em questão;

(b) sociocultural - análise das relações entre traduções e suas culturas fonte e alvo; a análise das traduções como eventos comunicativos interculturais;

(c) psicolinguística - análise do processo de tomada de decisão na mente do tradutor, da sua criatividade e história pessoal e como esses elementos afetam as suas escolhas;

(d) ética - análise dos aspectos ideológicos do ato tradutório e das traduções (p. 49; nossa tradução) ${ }^{2}$.

Essas diferentes perspectivas de pesquisa dos/nos Estudos da Tradução apontam para uma área em constante expansão, permitindo pesquisadores adentrar a área da tradução a partir de perspectivas diversas. Por ser interdisciplinar (MUNDAY, 2001), os Estudos da Tradução coadunam com os objetivos propostos pela Universidade Federal do Rio Grande do Norte (UFRN), em seu Plano de Desenvolvimento Institucional (PDI) (UFRN, 2010), permitindo, dessa forma, a sua estruturação na Universidade com vistas a formar não só tradutores, mas estudiosos da tradução.

O presente artigo tem, portanto, o objetivo de apresentar o início da estruturação dos Estudos da Tradução na UFRN. Para tanto, partindo do Plano de Desenvolvimento Institucional e do papel que a UFRN ocupa no estado do Rio Grande do Norte, traçaremos um histórico dos cursos de línguas estrangeiras na Universidade, pontuando como eles abarcam os Estudos da Tradução. Por fim, relataremos a experiência da primeira oficina de tradução, ministrada, de acordo com esse contexto, no segundo semestre de 2016. Iniciaremos, dessa forma, com a contextualização dos Estudos da Tradução na UFRN.

\footnotetext{
${ }^{2}$ Texto original: "(a) intertextual: analysis of the formal, semantic, stylistic and pragmatic relations between source and target texts, plus the background relations between the languages concerned; (b) socio-cultural: analysis of the relations between translations and their source and receiving cultures, the analysis of translations as intercultural communicative events; (c) psycholinguistic: the analysis of decision-making procedures in the translator's mind, of the translator's creativity, of the translator's personal history and how this affects choices; and (d) ethical: the analysis of ideological aspects of translating and translations".
} 


\section{Contextualização dos Estudos da Tradução na UFRN}

Nesta seção, buscaremos contextualizar os Estudos da Tradução na Universidade Federal do Rio Grande do Norte a partir dos documentos oficiais da Instituição e da sua relevância nas regiões norte e nordeste do Brasil. Por fim, apresentaremos os dois instrumentos que servem de apoio à proposta de sua estruturação.

\subsection{Estudos da Tradução e o Plano de Desenvolvimento Institucional}

A relação entre os Estudos da Tradução e a UFRN se estabelece inicialmente por meio da própria missão da universidade, definida, no Plano de Desenvolvimento Institucional (2010-2019), da seguinte forma:

A missão da Universidade Federal do Rio Grande do Norte, como instituição pública, é educar, produzir e disseminar o saber universal, preservar e difundir as artes e a cultura, e contribuir para o desenvolvimento humano, comprometendo-se com a justiça social, a sustentabilidade socioambiental, a democracia e a cidadania (UFRN, 2010, p. 11).

Além da sua missão, encontramos, ainda no PDI (UFRN, 2010, p. 41-42), objetivos relevantes para o desenvolvimento dos estudos da tradução: (i) a indissociabilidade ensino-pesquisa-extensão; (ii) a potencialização do princípio da flexibilidade com vistas à mobilidade interna e externa, local e internacional; (iii) a incorporação de novas tecnologias de informação e de comunicação no ensino, na pesquisa e na extensão, e (iv) o fortalecimento da atuação da UFRN em áreas estratégicas para o desenvolvimento socioeconômico do RN.

O plano estabelece a flexibilidade como princípio norteador das atividades pedagógicas, comportando as ideias de indissociabilidade das atividades de ensino, pesquisa e extensão; interdisciplinaridade, garantida pela integração dos conteúdos de várias disciplinas; a formação integrada à realidade social, de modo a ampliar as políticas de inclusão social; e a articulação teoria-prática.

A fim de respaldar alguns objetivos do PDI citados anteriormente, a UFRN conta com diversos programas estratégicos. Desses, os três mais relevantes para o 
desenvolvimento dos estudos da tradução são: o Departamento de Línguas e Literaturas Estrangeiras Modernas (DLLEM), o Instituto de Línguas, Literatura e Culturas Modernas - Ágora, e o Grupo de Pesquisa Multilíngue.

Assim, de acordo com a missão da universidade, visamos produzir, difundir e avançar as fronteiras do conhecimento, sem descuidar do desenvolvimento e da transformação da realidade local, da coletividade norte-rio-grandense, da região e do país.

Sendo a principal instituição de Ensino Superior do Rio Grande do Norte e uma das mais importantes do Norte e Nordeste, a UFRN tem apresentado altos investimentos institucionais para a abertura de cursos de Pós-Graduação Stricto Sensu. Durante os últimos cinco anos (2010 a 2015), a UFRN abriu 49 novos cursos, sendo 39 de Mestrado e 10 de Doutorado, integralizando, atualmente, 124 cursos de Mestrado (60) e Doutorado (41), além de 23 Mestrados Profissionais em funcionamento. A média das avaliações feitas pela CAPES foi de 3,9, com 12 programas conceituados em 5 ou 6. São eles: Psicobiologia, Ciência e Engenharia de Materiais, Física, Administração, Bioinformática, Biotecnologia, Ciências da Saúde, Contabilidade, Ecologia, Matemática, Psicologia, Sistemas e Computação.

A UFRN também coordena o maior grupo de projetos de pesquisa e de cursos de pós-graduação no estado do Rio Grande do Norte, sendo responsável por $45 \%$ das matrículas no Ensino Superior e por 92\% das matrículas nos cursos de pósgraduação stricto sensu.

$\mathrm{Na}$ grande área das Letras e Linguística, a UFRN oferece dois programas ligados ao Centro de Ciências Humanas Letras e Artes - CCHLA: o Programa de Pós-graduação em Estudos da Linguagem, criado em 1993, com Mestrado e Doutorado nota 4 (https://sigaa.ufrn.br/sigaa/public/programa/portal.jsf?id=65) e duas (02) unidades do PROFLETRAS (Natal e Currais Novos). É nesse contexto que os Estudos da Tradução na UFRN buscam se materializar por meio de uma proposta de criação do Programa de Pós-graduação em Estudos da Tradução, buscando agregar docentes de vários departamentos: Línguas e Literaturas Estrangeiras Modernas (DLLEM), Comunicação e Jornalismo, Escola de Ciência e Tecnologia e Centro de Educação, entre outros, e tem por meta complementar o quadro existente, investindo na interdisciplinaridade.

Como declarado anteriormente, dois programas são essenciais para a referida proposta: o Departamento de Línguas e Literaturas Estrangeiras Modernas (DLLEM) 
e o Grupo de Pesquisa Multilíngue. Diante disso, faz-se necessário elucidá-los separadamente, com o fito de, apresentando a sua história, evidenciar a sua relevância nesse processo.

\subsection{Estudos da Tradução e os instrumentos de apoio}

Criado pela Lei Federal $\mathrm{N}^{\circ}$. 3.849, a partir de um já existente curso denominado de Letras Neolatinas (Decreto Federal No. 40.573/1956), o atual Curso de Letras é um dos mais antigos da UFRN. Sua estrutura administrativa e seu currículo passaram por várias reformulações ao longo de sua história (1968, 1973, 1999, 2005) para atender às exigências e aos desafios das mudanças do nosso sistema, bem como de nossas concepções educacionais.

Até o ano de 2008, o Departamento de Letras (DLET) oferecia à comunidade acadêmica três licenciaturas: Língua Portuguesa e Literaturas, Língua Inglesa e Literaturas, Língua Francesa e Literaturas.

No contexto das demandas e das ofertas de um mercado de trabalho cada vez mais complexo e mais diversificado, o DLET aderiu ao REUNI - Programa de Apoio ao Plano de Reestruturação e Expansão das Universidades Federais implantando, no período de 2009.1, mais uma licenciatura: Língua Espanhola e Literaturas.

A globalização em sua abrangência e diversidade e o multilinguíssimo na era digital viram-se refletidos na política de internacionalização da UFRN, proporcionando o aumento do número de docentes e da oferta de línguas e culturas estudadas e ensinadas no Departamento de Línguas e Literaturas Estrangeiras Modernas (DLLEM) e no Instituto Ágora. Por meio dessa política foi possível a contratação de dois professores de língua/cultura alemã e dois professores de português como língua não materna.

O DLLEM, criado oficialmente em fevereiro de 2010 por desmembramento do DLET, reúne os professores de línguas e literaturas estrangeiras da UFRN e apresenta uma biografia recente própria, antecedida por uma história de convivência no âmbito de um único departamento - o DLET — na condução das atividades referentes ao Curso de Letras em suas diversas habilitações.

Em 2016, para atender às Novas Diretrizes Curriculares para a formação inicial em nível superior do MEC (2015), as habilitações deixaram de existir, 
tornando-se cursos. Assim, o DLLEM passou a trabalhar com três licenciaturas: de Língua Inglesa, Língua Francesa e Língua Espanhola, e o DLET, com duas: Língua Portuguesa e Língua Portuguesa e Libras, todas ainda em fase de elaboração dos novos Projetos Pedagógicos de Curso (PPC) e de credenciamento pelo MEC.

Vale salientar que os três novos cursos de Línguas Estrangeiras, assim como o de Libras, antes habilitações, contam, em suas estruturas curriculares, com disciplinas de tradução, sejam optativas ou obrigatórias. Ademais, membros do Grupo de Pesquisa Multilíngue, apresentado a seguir, vêm oferecendo cursos de extensão em tradução, além de cursos e oficinas que tangenciam as questões tradutórias.

\subsection{O Grupo de Pesquisa Multilíngue}

O Grupo de Pesquisa Multilíngue foi fundado em 2016 pela Prof. ${ }^{a}$ Katia A. F. de Camargo. Suas ações englobam Pesquisa, Ensino e Extensão plenamente alinhados com as metas, políticas e programas da UFRN anteriormente citados. Essas ações buscam dar resposta a um desafio essencial da UFRN no seu propósito de ser uma Universidade de inserção internacional.

A partir desse contexto institucional no que tange à organização dos Estudos da Tradução na UFRN, faz-se necessário apresentar, mesmo que de forma sintética, alguns posicionamentos teóricos relativos à tradução e às competências relativas ao tradutor, o tema da próxima seção.

\section{Tradução multilíngue: considerações teóricas}

Houve um salto qualitativo e quantitativo nos estudos sobre tradução, primeiramente em meados dos anos de 1950 e, em seguida, na década de 1990, o que provocou um aumento de interesse pela pesquisa nessa área. No entanto, Chesterman (1988) afirma existirem muitos estudos e experimentos que tratam de questões muito isoladas ou de pouca relevância científica e critica ainda a falta de embasamento teórico na análise dos resultados ${ }^{3}$.

Diante disso, Amparo Hurtado Albir (2001, p. 199) afirma que

\footnotetext{
${ }^{3}$ Para o caso específico do Brasil, ver comentários de John Milton (2014).
} 
Consideramos premente que se busque a relevância dos dados da investigação para a Tradutologia como um todo, que se saiba escolher os métodos e os instrumentos com base no objeto de estudo e nos objetivos propostos e que se encoraje a réplica e o contato entre os investigadores ${ }^{4}$.

É possível definir a tradução - fundamentalmente a tradução escrita - como um processo interpretativo e comunicativo de reformulação de um texto em um contexto social (ALBIR, 1999). Já o traduzir, de acordo com Gutt (1991), é um processo mental que consta de duas fases: compreender e reformular, sendo o tradutor, no processo de comunicação, um receptor e um emissor especial. Além disso, como parte da premissa de que terá de traduzir o texto, o tradutor faz uma leitura muito atenta deste, voltada à finalidade específica da tradução. Por outro lado, geralmente o tradutor não pertence a uma das comunidades linguísticoculturais interligadas pelo processo de tradução, seja esta a comunidade da língua de partida, seja a comunidade da língua de chegada. Há distâncias que separam, então, o tradutor do receptor normal do texto na língua de partida e do emissor normal na língua meta.

Dependendo da finalidade da tradução, é possível adotar diferentes métodos (HURTADO ALBIR, 2001, p. 54). No método interpretativo-comunicativo, o sentido do texto original é compreendido e reformulado, mantendo a mesma função e gênero do original, e procurando reproduzir um efeito similar no destinatário. No método literal, faz-se uma tradução palavra por palavra, frase por frase, sintagma por sintagma, com a finalidade de reproduzir o sistema linguístico de partida e a forma do texto original. Já na tradução livre, é possível mudar o gênero textual, passando de prosa a verso, mudar o registro, o dialeto, etc. No método filológico, por sua vez, são incluídas, na tradução, observações eruditas, notas de rodapé, comentários que procuram contextualizar o texto, etc.

No processo de tradução, normalmente o tradutor encontra diversos tipos de problemas; as estratégias de tradução adotadas durante o processo (LÖRSCHER, 1991) são respostas que visam encontrar uma solução para eles.

\footnotetext{
4 Texto original: "Consideramos acuciante que se busque la relevancia de los datos de la investigación para el conjunto de la Traductología, que se sepa elegir los métodos y los instrumentos en función del objeto de estudio y los objetivos planteados, y que se fomente la réplica y el contacto entre los investigadores".
} 
Por outro lado, como foi explicitado na definição acima, a tradução é uma operação textual e, por isso, exige, da parte do tradutor, o domínio de diversos gêneros e tipologias textuais (HATIM; MASON, 1990, 1997), bem como o desenvolvimento de competências pragmáticas e discursivas adequadas nas duas línguas envolvidas no processo de tradução. Além disso, Hartman (1981) considera extremamente necessário incluir os conhecimentos da linguística textual no âmbito de uma textologia comparada ou textologia contrastiva, a fim de favorecer a prática do tradutor e a qualidade do resultado do seu trabalho. A análise textual comparada do produto desse processo, quer dizer, a análise comparativa do texto traduzido e do texto original, permite detectar quais são as técnicas de tradução usadas com mais frequência pelos tradutores. Nida e Taber (1969) enumeram algumas dessas técnicas, usadas já no passado pelos tradutores da Bíblia: adaptação, ampliação, compensação, criação discursiva, equivalência, generalização, empréstimo, etc.

Um elemento chave na definição de tradução é o contexto. A tradução é um ato comunicativo desenvolvido em dois espaços ou contextos situacionais diferentes, e às vezes em espaços socioculturais muito distantes entre si. Justamente por isso constitui um ato comunicativo sumamente complexo que detém um caráter pragmático muito peculiar. É, de fato, um enorme desafio traduzir certos detalhes da discursividade da cultura brasileira, e da cultura nordestina em particular, como, por exemplo, as estratégias para exprimir rejeição ou para criticar, para a norma escrita culta em espanhol, em inglês ou em francês.

Levando em consideração as ideias anteriores e adotando agora um ponto de vista centrado na questão do ensino da tradução e nos variados problemas didáticos que ela suscita, é atinado supor que a formação de tradutores demanda não apenas o desenvolvimento das competências comunicativas (CANALE, 2013; GARGALLO, 1999) na língua de partida e na língua de chegada (gramatical, sociolinguística, discursiva, estratégica), ou seja, a formação de falantes bilíngues, mas também o desenvolvimento de outras competências específicas da tradução. Se considerarmos, além disso, que a tradução é um conhecimento operacional, um savoir-faire, é lógico inferir que essa habilidade, a habilidade de traduzir, bem como as competências que ela engloba, só poderão ser desenvolvidas por meio da prática.

Por fim, Albir (1999), pesquisadora principal do grupo PACTE, do Departamento de Tradução e Interpretação da Universidade Autónoma de 
Barcelona, afirma que, além das competências comunicativas nas duas línguas em que traduz, o tradutor precisa do desenvolvimento de competências extralinguísticas, de transferência profissional, psicológica e fisiológica, bem como da competência estratégica ${ }^{5}$.

Foi com base, portanto, no que se configura $o$ ato da tradução e as competências inerentes ao tradutor que se criou uma oficina de tradução multilíngue como parte dos primeiros passos para o processo de criação dos estudos de tradução na UFRN. Esse é o tema da próxima seção.

\section{Mise en place: Oficina de tradução multilíngue.}

Neunzig e Tanqueiro (2007) afirmam que:

Quando uma ciência como a tradutologia, cujos objetivos investigativos não apontam nem a uma descrição e controle do mundo (como fazem as Ciências Naturais) nem ao comportamento social humano (Ciências Sociais), nem à análise ou a interpretação de uma intervenção real dos humanos (Ciências Históricas, Jurídicas, Filológicas), mas apenas representam, em definitivo, a busca de um estado ideal, resultado potencial da intervenção humana, esta terá que desenvolver uma forma de abstração teórica e buscar um novo caminho de investigação, um procedimento investigativo que não esteja focado unicamente na exatidão postulada pelo "método científico", senão que privilegie a praticabilidade, a transparência e a relevância do 'processo científico' [...] (p. 25) ${ }^{6}$.

Pensando nisso, ao longo do segundo semestre de 2016, foi ministrada a primeira Oficina de Tradução Multilíngue (Português, francês e Espanhol), seguindo o aporte teórico aqui apresentado. A oficina teve um total de 30 horas, com participação de 13 alunos, todos discentes e/ou egressos das licenciaturas em línguas estrangeiras da UFRN. Os encontros eram semanais e, como material

\footnotetext{
${ }^{5}$ Sobre o enfoque mais direcionado ao papel do tradutor nos estudos da tradução, ver Chesterman (2014), em que apresenta os Estudos do Tradutor.

- Texto original: "Cuando una ciencia como la tradutología, cuyos objetivos investigadores no apuntan ni a una descripción y control del mundo (como lo hacen las ciencias naturales), ni del comportamiento humano (ciencias sociales), ni al análisis o a la interpretación de una intervención real de los humanos (ciencias históricas, jurídicas, filológicas), sino que representan, en definitiva, la búsqueda de un estado ideal, resultado potencial de la intervención humana, ésta tendrá que desarrollar una forma de abstracción teórica y buscar un nuevo camino de investigación, un procedimiento investigador que no esté enfocado solamente a la exactitud postulada por el 'método científico'[...]".
} 
didático, adaptamos, para o falante brasileiro, o manual Aprender a traducir del francés al español: competencias y tareas para la iniciación a la traducción, de Albir (2015).

Nessa oficina pudemos trabalhar três unidades didáticas: 1. Conhecimentos prévios e expectativas: O que vem a ser a tradução?; 2. A finalidade comunicativa da tradução: Traduzir é comunicar; 3. A profissão de tradutor: competências, tarefas e mercado de trabalho. De imediato, podemos afirmar que apesar de haver a disciplina de tradução nas três licenciaturas de línguas estrangeiras da UFRN, pudemos identificar certa dificuldade dos participantes no processo tradutório.

De início, fizemos um questionário dividido em cinco partes: 1. Meus conhecimentos atuais; 2. O eu gostaria de ser; 3. Minha concepção de tradutor; 4. O que eu penso sobre a tradução e 5. Tradução.

Na parte 4 havia duas questões que achamos relevantes destacar aqui:

a. Segundo você, qual seria a maior dificuldade da tradução?

b. Como você definiria tradução?

Para a questão (a), tivemos como resposta mais frequente a dificuldade em traduzir expressões culturalmente marcadas e a questão da fidelidade em relação ao original. Seguem algumas das respostas dos participantes:

P1: "Conservar a mensagem a ser transmitida levando em consideração os contextos".

P2: "A tradução de expressões idiomáticas."

P3: "Acredito que seja o limitado vocabulário".

P4: "Entender o sentido do texto a ser traduzido, ter conhecimento das expressões idiomáticas e identificar os referenciais culturais específicos daquela língua contidos no texto (principalmente os textos literários)".

P5: "A fidelidade ao texto original".

P6: "A tentativa, não poucas vezes falhas, de manter-se fiel ao original".

Já para a questão (b), encontramos como cerne da definição do que seria tradução a transposição de textos de uma língua para outra, possibilitando, assim, o acesso ao conhecimento. Os exemplos abaixo revelam esse pensamento:

P3: "Tradução é uma forma de não limitar o conhecimento". 
P4: "Trabalho de aproximação de significado de uma língua a outra, de uma cultura a outra".

P5: "Tradução seria uma maneira de dar acesso a textos em outras línguas para aqueles que não dominam a língua estrangeira".

P6: "O ato de tornar acessível para quem não tinha acesso antes".

P7: "Capacidade de expressar as ideias e os pensamentos de um autor, de uma obra".

$\mathrm{Na}$ parte 5 do questionário, relativa à tradução, pedimos que o aluno traduzisse um pequeno texto adaptado do Le Figaro, de 5 de maio de 1990. Eles podiam utilizar ou não os dicionários a que tinham acesso eletronicamente e/ou consultar os colegas. Entretanto, não demos indicação alguma, pois nossa intenção era ver como os alunos se portavam diante de um texto a ser traduzido. Segue o fait-divers:

\section{Texto 1}

MADONNA est furieuse. Lors de son dernier séjour à Paris, elle avait gentiment offert à la femme de chambre du palace, où elle était descendue, une partie de sa garde-robe. Elle vient d'apprendre que cette soubrette, qui affirmait être une inconditionnelle, a revendu tous ces vêtements à moitié prix.

\section{Adaptado do Le Figaro (5/5/1990)}

Dos 13 alunos que participaram da oficina (dos quais 11 estavam no último ano da licenciatura ou já eram formados e apenas 02 estavam no primeiro ano do curso), apenas 03 procuraram traduzir o texto sem deixar lacunas, 02 traduziram apenas a primeira parte, e outros 02 não conseguiram traduzir. Aqui estão alguns de seus comentários: "Não vou traduzir porque há muito vocabulário que desconheço [...]; Estou iniciando o $2^{\circ}$ semestre de francês". A maioria deixou lacunas em termos como "était descendue", "soubrette", "inconditionnelle", mas a maior dificuldade se mostrou na falta de compreensão do texto original e no desconhecimento da língua de chegada, a saber, a língua materna.

A seguir, na tradução elaborada pelo P6 vemos que a grande preocupação do aluno foi transmitir a mensagem do texto, fazendo adaptações dos termos que desconhecia: 
P6. "Madonna está furiosa. Durante sua última estadia em Paris, ela tinha gentilmente presenteado a camareira do local onde estava hospedada uma parte de seu guarda-roupas. Ela acabou de saber que esta "espertinha", que afirmava ser uma grande fã, vendeu todas suas roupas a metade do preço."

O participante P5 foi aquele que elaborou uma tradução, digamos, mais próxima do original, mais literal:

P5. "Madonna está furiosa. Na última vez que esteve em Paris, ela gentilmente deu à camareira do palácio, onde ela ficou hospedada, uma parte do seu guarda-roupa. Ela acaba de saber que a vigarista, que afirma ser uma fã incondicional, havia revendido todas as roupas pela metade do preço."

Já o participante P3 não só não entendeu o texto, como sua tradução não faz nenhum sentido na língua de chegada:

P3. "Madonna está furiosa. Pois é seus últimos dias em Paris. Ela foi gentil em oferecer o quarto do palácio, onde ela era descendente, uma parte ... Ela vem aprender que essa..., que afirma ser uma incondicional, a revender todas suas roupas... preço".

Ao serem questionados sobre as dificuldades encontradas, tivemos como principal resposta o desconhecimento de palavras do texto e a "dificuldade de adequar as orações de forma coerente para o Português".

Outros exercícios desse tipo foram realizados ao longo da oficina, com discussão em sala e reescrita da tradução em casa. Nesses casos, os resultados foram melhores, mas ainda encontramos problemas de compreensão. Exemplo de tarefa realizada:

\section{Texto 2: Miraculeux}

La sacristaine de Saint-Roch n'en revient pas. En nettoyant l'église, la semaine dernière, elle a découvert, à côté d'un autel, un sac en plastique contenant 7.500 euros. Elle les a donnés au curé, qui les a, après trois jours, donnés à la police, qui 
n'explique toujours pas le mystère. Si personne ne les réclame d'ici un an et un jour, le don du ciel miraculeux reviendra à la paroissienne.

Adaptado de Libération (30/4/1990)

Tradução elaborada por P2

"Milagre na França"

A sacristã da igreja de São Roque ainda não está acreditando. No momento em que fazia a limpeza, na semana passada, ela encontrou, ao lado do altar, um saco plástico contendo 7.500 euros. A quantia foi passada à polícia que não conseguiu encontrar uma explicação para o mistério. Se o dono do montante não aparecer no período de um ano e um dia, o dinheiro será revertido para a religiosa".

Percebemos que o aluno traduziu os nomes de lugares, que eliminou a palavra igreja que consta do início da segunda frase, assim como grande parte da terceira frase: "Elle les a donnés au curé, qui les a, après trois jours..." e uma parte da última frase: "le don du ciel miraculeux...", frase que dá título ao artigo. Propositadamente ou não, o aluno deixou de fora quase todas as passagens ligadas à Igreja, fixando-se no essencial da mensagem a ser transmitida.

Outro exemplo é o do participante P1:

"Sacola milagrosa"

A sacristã de Saint-Roch (igreja localizada em Paris - França) não acredita no que aconteceu. Realizando a limpeza da igreja, na semana passada, ela descobriu, ao lado do altar uma sacola plástica contendo 7.500 euros. Ela entregou o dinheiro ao padre. Após três dias, ele entregou a polícia, que não conseguiu desvendar o mistério. Se ninguém sentir falta da sacola daqui a um ano e um dia, o dom "milagroso" será revertido à paróquia".

Neste caso, P1 acrescentou uma série de elementos e informações que não constavam no texto original; compreendeu de maneira equivocada um advérbio de tempo: dentro [do período] de um ano e um dia; equivocou-se na tradução do termo paroissienne - paróquia e não por religiosa, como em P2, ou por beata, talvez por uma suposta transparência em relação ao português. 
Todos os exercícios de tradução escrita realizados na oficina foram discutidos em sala. O objetivo não era dizer se uma tradução estava boa ou não, correta ou não, mas mostrar o seu papel enquanto elemento de comunicação; discutir os diferentes termos e interpretações encontrados no momento da tradução; imaginar o público leitor e a adequação da tradução em função dele; e aprender a escolher e utilizar ferramentas como dicionários bilíngues e monolíngues.

No último encontro, fizemos uma autoavaliação composta por quatro questões que buscavam verificar: $\mathrm{O}$ que necessito levar em conta para aprender a traduzir?

Nas respostas encontramos:

Para traduzir bem necessito levar em conta...

"... aprendizagem das estruturas das línguas. A utilização de como devo usar as ferramentas como dicionários eletrônicos, de papel e outros."

"... a língua do outro, quem irá ler a tradução. A mensagem deverá ser clara e objetiva."

"Objetivo da tradução e sua adequação".

"Os métodos e ferramentas de tradução, o destino que será dado a ela (para qual público), o significado de determinadas expressões e sua equivalência na língua de chegada".

"Ler e/ou terminar os livros que abordam a temática da tradução; organizar um vocabulário de palavras e/ou expressões recorrentes."

Para poder traduzir bem necessito melhorar...

"Conhecer melhor a minha língua, expressões..."

"...a língua estrangeira. O conhecimento de cultura do outro."

"Nível das línguas (partida e chegada), conhecer mais sobre ferramentas e dicionários, praticar."

"O vocabulário de ambas as línguas e suas regras específicas, os aspectos culturais ligados a cada uma delas, a prática da leitura de textos relacionados a tradução [...]."

"Conhecimento da língua de chegada; a pesquisa em livros e dicionários impressos ou virtuais." 
Foi possível perceber, dessa forma, que os alunos, possivelmente desconhecedores das perspectivas dos Estudos da Tradução, mostraram ora preocupados com o texto fonte, por meio de uma tradução mais "literal" [uma perspectiva mais intertextual (CHESTERMAN, 1997)], ora preocupados com um texto mais comunicativo, mesmo que omitissem palavras-chave do texto [uma perspectiva mais sociocultural (CHESTERMAN, 1997)], e nós, focados no processo de tradução dos alunos e na suas tomadas de decisão enquanto tradutores, optamos por uma perspectiva mais psicolinguística (CHESTERMAN, 1997). De forma geral, ficou clara, para os alunos/tradutores, a importância dos Estudos da Tradução, compreendida como um evento comunicativo e perpassada por posicionamentos teóricos, linguísticos, sociais, culturais e éticos, o que torna a área da tradutologia uma área em constante devir.

\section{À guisa de conclusão...}

Este artigo teve o objetivo de apresentar a estruturação dos Estudos da Tradução na UFRN com vistas a formar não só tradutores, mas estudiosos da tradução. Para tal, em primeiro lugar, mostramos como essa estruturação responde a uma necessidade institucional e local e se coaduna com os próprios documentos oficiais da Universidade. Em seguida, discutimos, de forma concisa, a tradução como ato comunicativo e alguns dos diferentes métodos utilizados, bem como as habilidades necessárias para esse processo de comunicação. Por fim, apresentamos a Oficina de Tradução Multilíngue, que ocorreu no segundo semestre de 2016, e alguns excertos das atividades feitas pelos participantes.

Diante disso, é possível concluir que os estudos da tradução na UFRN começam a se estruturar, e a primeira oficina ministrada dentro desse contexto nos mostrou que há muito trabalho a ser feito no que tange à formação de massa crítica. O relato dessa oficina nos revela a necessidade em se trabalhar não só a língua estrangeira, mas também e, sobretudo, a língua de chegada para que, ao final de cada curso e oficina na área de tradução, os participantes possam, ao menos, perceber o que precisam aprimorar para seguir em frente nessa campo tão rico e vasto que são os Estudos da Tradução. 


\section{Referências}

CANALE, M. From communicative competence to communicative language pedagogy. In: RICHARDS, J.; SCHMIDT, R. Language and communication. New York: Routledge, 2013, p. 2-27.

CHESTERMAN, A. Memes of translation: the spread of ideas in translation theory. Amsterdam: John Benjamins, 1997.

CHESTERMAN, A. O nome e a natureza dos estudos do tradutor. Belas Infiéis, v. 3, n. 2, p. 33-42, 2014. Disponível em: <periodicos.unb.br/index.php/belasinfieis/ article/download/13003/9152>. Acesso em: 11 jul. 2017.

GARGALLO, I. S. Lingüística aplicada a la enseñanza-aprendizaje del español como lengua extranjera. Madrid: Arco/Libros, 1999.

GUTT, E.-A. Translation and relevance: cognition and context. Oxford: Basil Blackwell, 1991.

HATIM, B; MASON, I. Discourse and the translator. Londres: Longman, 1990.

HATIM, B; MASON, I. The translator as communicator. Londres: Routledge, 1987.

HURTADO ALBIR, A. Enseñar a traducir: Metodología en la formación de traductores e intérpretes: teoría y fichas prácticas. Madrid: Edelsa Grupo Didascalia, 1999.

HURTADO ALBIR, A. Traducción y traductología: introducción a la traductología. Madrid: Ed. Catedra, 2001.

HURTADO ALBIR, A. Aprender a traducir del francés al español: competencias y tareas para la iniciación a la traducción. Castelló de la Plana: Publicacions de la Universitat Jaume I; Madrid: Edelsa, 2015.

LÖRSCHER, W. Translation performance, translation process and translation strategies. Tubingen: Gunter Narr Verlag, 1991.

MILTON, J. Editorial: Los Estudios de Traducción en Brasil. Mutatis Mutandis. Vol. 7, n. 1, p. 3-15, 2014. Disponível em: <https://dialnet.unirioja.es/descarga/articulo/ 5790738.pdf>. Acesso em: 13 dez. 2016.

MUNDAY, J. Introducing translation studies. New York: Routledge, 2001.

NEUNZIG, W.; TANQUEIRO, H. Estudios empíricos en traducción: enfoques y métodos. Girona: Documenta Universitaria, 2007.

NIDA, E. A.; TABER, Ch. Theory and practice of translation. Leiden: E.J. Brill, 1969. 
UFRN. Plano de desenvolvimento institucional: 2010-2019. Natal: UFRN, 2010. Disponível em: <https://sistemas.ufrn.br/shared/verArquivo?idArquivo=637863\&key= d52c937a619f6f6 ecb4624 a62654f857>. Acesso em: 15 jan. 2017.

Recebido em 18/07/2017

Aceito em 31/07/2017

Publicado em 12/08/2017 